\title{
An comparative study on Conventional concrete and Engineered Cementitious Composites (ECC-PVA)- REVIEW
}

\author{
S.Uttamraj ${ }^{1}$, K. Ashwanth ${ }^{2}$, Dr. Md.Rafeeq ${ }^{3}$ \\ ${ }^{I}$ (Research scholar, JNTUH/, INDIA) \\ ${ }^{2}$ (civil dept, AURORA, Bandlagudal, INDIA) \\ 3(Research Officer TSERL Himayat SagarINDIA)
}

\begin{abstract}
Engineered Cementitious Composites abbreviated as ECC. This material is capable to exhibit considerably enhanced flexibility. An ECC has a strain capacity of more than 3 percent and thus acts more like a ductile metal rather than like a brittle glass. A bendable concrete is composed of all the ingredients of a traditional concrete minus coarse aggregates or crushed stones and is reinforced with micromechanically designed polymer fibers Bendable concrete also known as Engineered Cementitious Composites abbreviated as ECC is class of ultra-ductile fiber reinforced cementitious composites, characterized by high ductility and tight crack width control. This material is capable to exhibit considerably enhanced flexibility. An ECC has a strain capacity of more than 3\% to 5\% compared to $0.01 \%$ of normal concrete and thus acts more like a ductile metal rather than like a brittle glass. A ECC is reinforced with micromechanically designed polymer fibres.PVA. Polyvinyl alcohol (PVA) fiber is considered as one of the most suitable polymeric fibers to be used as the reinforcement of engineered cementitious composites (ECC), showing an extensive strain hardening behaviour of the composites, can be used to reduce resources and funds for rehabilitation of structure. At the starting this fiber concrete can be double the cost as compare to conventional concrete but as it can amplify the duration of structure, it will be less costlier than the conventional concrete, Conventional concretes are almost un-bendable and have a strain capacity of only 0.1 percent making them highly brittle and rigid. This lack of bendability is a major cause of failure under strain Plain concrete possesses a very low tensile strength, low ductility and little resistance to cracking. Internal micro-cracks are inherently present in the concrete (due to drying shrinkage) and its poor tensile strength is due to the propagation of these cracks (under loading), eventually leading to brittle failure of the concrete. This review paper presents comparative study on conventional concrete and Engineered Cementitious Composites (ECC), by comparing strength properties like workability youngs modulus and hardened concrete properties as compressive strength, split tensile strength flexural strength. Also stating the current scenario about various active research that are taking place around the world on Engineered Cementitious Composites (ECC) by incorporating Polyvinyl Alcohol (PVA).
\end{abstract}

Keywords: Engineered Cementitious Composites (ECC), polyvinyl alcohol (PVA), young's modulus, compressive strength, split tensile strength flexural strength, fly ash

\section{Introduction}

Conventional concretes are almost un-bendable and have a strain capacity of only 0.1 percent making them highly brittle and rigid. This lack of bendability is a major cause of failure under strain and has been a pushing factor in the development of an elegant material namely, Engineered Cementitious Composites abbreviated as ECC. This material is capable to exhibit considerably enhanced flexibility. An ECC has a strain capacity of more than 3 percent and thus acts more like a ductile metal A bendable concrete is composed of all the ingredients of a traditional concrete minus coarse aggregates or crushed stones and is reinforced with micromechanically designed polymer fibers. Polyvinyl alcohol or PVA) is a water-soluble synthetic polymer. Polyvinyl alcohol has high tensile strength and flexibility. Prior to use in ECC, these fibers are slick-coated. Although complete friction elimination is not possible by using any slick coating, the emphasis is to reduce the friction at its maximumPolyvinyl alcohol (PVOH, or PVA) is a water-soluble synthetic polymer.Polyvinyl alcohol has high tensile strength and flexibility and are well-suited to be used in making ECC. PVA is basically an adhesive which is used to formulate glue . Engineered cementitious composites are designed to produce a strong and flexible material that can be used in numerous applications where fiber reinforced concrete may not be suitable. This is a recent development, and further studies are still in progress. The material ingredients of engineered cementitious composite are similar to that of fiber reinforced concrete, including cement, sand, water, fiber, and a few chemical additives. Unlike the fiber reinforced concrete, the engineered cementitious composites do not include large volume of fiber. The mixing procedure of ECC is similar to that employed for the normal concrete. The ECC are economical by a reduction in the usage of fiber while maintaining the desired

International Conference on Recent Innovations in Civil \& Mechanical Engineering

$19 \mid$ Page

[i-CAM2K16] DOI: 10.9790/1684-16053011925 
An comparative study on Conventional concrete and Engineered Cementitious Composites (ECC-

characteristics of strength and ductility. The basic difference in the properties of ECC and fiber reinforced concrete is that after cracking the ECC strain hardens while the fiber reinforced concrete does not exhibit such a behavior. In fiber reinforced concrete, the crack develops with the rupture of the fibers due to which the stress bearing capability is decreased. ECC has higher amount of cement due to the absence of coarse aggregate in the mix proportion than fiber reinforced concrete

\section{REVIEW S}

1)This paper explores experimentally the mechanical properties of a new hybrid fibre-reinforced engineered cementitious composite (ECC) material reinforced with $1.75 \%$ polyvinyl alcohol (PVA) fibre and $0.58 \%$ steel (SE) fibre. The development of this new ECC aims to achieve better impact resistance. A series of experiments were carried out to determine the compressive strength, Young's modulus, modulus of rupture, and tensile characteristics of the new material Material properties of the ECC reinforced with 1.5\% PVA fibre and $0.5 \%$ SE fibre, which is denoted as the reference mix in this paper and has been claimed to be the most promising composition of fibres for impact resistance was also tested in this study for comparison and for determination of effect of fibre volume fraction on the material properties. It was concluded that the new ECC reinforced with $1.75 \%$ polyvinyl alcohol (PVA) fibre and $0.58 \%$ steel (SE) fibre exhibits improved strength and strain capability than the reference ECC, which are both essential for improving impact resistance. Conclusion This study has explored experimentally the mechanical properties of a new hybrid fibre-reinforced engineered cementitious composite(ECC) It is found that enewECC_M2mixexhibitsimproved compressivestrength, Young's modulus, ultimate flexural strength, flexural strain, tensile strength at first crack and ultimate tensile strength than the ECC_M1 material. However, it is also found that the phase of strain hardeningofECC_M2is slightlyshorterthanthatof ECC_M1.Itcan be seen from this study that increasing the volume fraction of SE fibres in hybrid fibre-reinforced ECC $\bar{C}$ produces greater strength, but increasing the amount of the PVA fibre does not results in stronger strain capacity. it is found that the tensile characteristics of both ECC mixes are rate dependent, and the tensile strength at first crack and the ultimate tensile strength increases with the increase of the strain rate, whereas the strain capacity decreases with the increase of the strain rate. Material properties of a new hybrid $\square$ brereinforced engineered cementitious composite

2) Concrete is good in compression but if any type of strain applied to it, it starts to fail. Where the steel is good tension. It can bear the deflection up to its elastic limits. This project is based on behavior of engineered cementitious composited (ECC) when it is replaced with the different amount of Polyvinyl Alcohol (PVA) Fibers. As for research, PVA fibers is used with cementitious up to $2 \%$ to evaluate the optimum amount of fiber on which we can find the maximum compressive, tensile and flexural strength. PVA is basically an adhesive which is used to formulate glue. Generally due to excessive loading, cracks develops which concludes to successive damage to the structural component. In research plasticizer is used to increase workability. With the help of optimum amount of PVA fibers, it can limit the crack widths up to $60 \mu \mathrm{m}$ to $100 \mu \mathrm{m}$ Also can be used to reduce resources and funds for rehabilitation of structure. At the starting this fiber concrete can be double the cost as compare to conventional concrete but as it can amplify the duration of structure, it will be less costlier than the conventional concrete From this research, there is need of developing a new class of ECC which has the strain-hardening property but which can be processed with conventional equipment. It is demonstrated that such a material, termed engineered cementitious composites or ECCs, can be designed based on micromechanical principles. The significant properties of ECC-Concrete are ductility, durability, compressive strength, and self-consolidation. Polyvinyl Alcohol fibers dose not disperse properly in the mixing water. Addition of fibers to dry mix was found to be more practical. It is found that presence of fibers can decrease the alertness of the failure, which mainly occurs due to spalling or brittleness of the conventional concrete. Where fiber concrete can be fail due to protruding at the transverse direction. Compressive strength increases with increasing fiber content. But when it reaches up to its optimum value, it starts decreasing with the increasing content of fiber.In split tensile strength, it escalate due to Polyvinyl Alcohol fibers at 28 days is approximately $50 \%$ higher than 7 day's strength. Flexural strength also increases as fiber content increases. During the test, it was perceived that PVA-ECC specimen has greater crack control as demonstrated by reduction in crack widths and crack spacing.Fibers reduces the w/c ratio which leads to the low workability. There is considerable improvement in the post-cracking behavior of concretes containing fibers. Although in the fiberreinforced concrete the ultimate tensile strengths do not increase appreciably, the tensile strains at rupture do. Compared to plain concrete, fiber reinforced concrete is much tougher and more resistant to impact. Evaluation of Engineering Cementitious Composites (ECC) With Different Percentage of Fibers -Bhaumik Merchant june 2015

3) This paper reports on the development of ECC, taking into account environmental sustainability considerations. ECC is representing a unique class of high-performance fibre-reinforced cementitious composites possessing high tensile and durability properties. With the ultra-high volumes of fly ash up to $85 \%$ 
by weight of cement replacement, are proposed in this research paper While micromechanical modelling is applied in the material design process, main focus of this study is placed on the fly ash content effect on material microstructure and mechanical properties altering process. Experimental results shown that HVFA ECCs, while addition high volumes of recycled fly ash, which can retain an approximately 2 to $3 \%$ of long-term tensile ductility. Significantly, both the free drying shrinkage and crack width are reduced with an increasing volume of the fly ash amount, which results in the improvement of long-term durability of structures made by HVFA-ECC. Micromechanical modelling analysis indicates the increase in fiber and matrix interface behaviour is responsible for the tight crack width. HVF-ECCs show an improvement robustness by achieving more saturated multiple cracking while the use of industrial waste stream material instead of cement resulted in reducing environmental impact through the use. Reported by Yingzi Yang, En-Hua Yang, and Victor C. Li

4) Over the past decade, various experiments had been made in field of creating engineered cementitious composites (ECC) with superb performance in tensile ductility, in the range of several hundred times than the normal concrete or fiber reinforced concrete (FRC). ECC design has been built on the basis of the relationship between the material microstructures, properties, processing and materials performance. This concept of material microstructures modeling was worked out very well in creating the various versions of ECC that can be prepared by using different materials as self-consolidating, casting, extrusion, and spraying. This research describes the initial attempt in creating greener ECCs, ECCs that maintain the extreme tensile ductility characteristics, but which also incorporate adopting various environmental considerations in the design and development of these materials for infrastructure applications. Sustainable ECC material design adopts the microstructure design tailoring based on various social, environmental, and economic aspects. The framework for developing green ECC has been described. Some preliminary experimental results of the cement substitution with various mineral ad mixtures and also the fiber substitution with industrial by-products and their effects on the mechanical properties are reported. Concrete and ECC show very significant differences in both fresh and mechanical properties . ECC production is resulting in a greater environmental burdens than concrete due to high content of cement usage of standard ECC, and the inclusion of various synthetic fibers. ECC material is made only sustainable in terms of the usage of solid waste produced, flyash which is an industrial waste produced from coal-based power plants. The analysis suggests that the reduction in the usage cement content of ECC and PVA fibers may be the possible methods of increasing the economy and sustainability of greener ECC material. In this research one type of bottom ash and Two types of fly ash i.e. Fine fly ash is representing a two special type Class $\mathrm{C}$ fly ash and class $\mathrm{F}$ fly ash.The Class $\mathrm{C}$ fly ash with particle size of average $2 \mu \mathrm{m}$ and high calcium content, whose particle size is much smaller than general class $\mathrm{F}$ fly ash of average $13 \mu \mathrm{m}$ are investigated, and the Fine fly ash is representing a special type of Class $\mathrm{C}$ fly ash with high amount calcium content, and particle size of average $2 \mu \mathrm{m}$ which is much are much smaller than class $\mathrm{F}$ fly ash of average $13 \mu \mathrm{m}$ and the bottom ash of average particle size $50 \mu \mathrm{m}$ is used. Bottom ash, due to its low pozzolonic reactivity, this leads to both lower early but long-term strength in the ECC. Mapping of the greener ECC properties to the required properties for specific interest of infrastructural applications resulted to a minimum performance reduction in the performance of infrastructure, while greatly enhancing the life and sustainability indices. .

\section{Reported by Victor C. Li, Michael}

Lepech et al

\section{Methodology And Experimental Procedure}

This includes materials and specifications the tests performed on ECC as per relevant standards and details of making and testing of ECC.And conventional concrete with the same mix proportions We also have replaced cement with $30 \%$ of fly ash.On the basis of literature reviews. It specifies the materials, mix proportions, tests to be performed, period of testing. The materials used for preparing PVA mixed ECC concrete are fly ash, aggregate - maximum size of $10 \mathrm{~mm}$, river sand, plasticizer as conplast30, PVA fibers with range of $0.5 \%$ to $2 \%$ and water.. In the paper four different percentage of fibers were taken to evaluate and to optimize the exact range of PVA fibers which is feasible for concrete, as strength wise. Was compare with conventional concrete same fly ash content was tested Mixture proportions and properties of concrete used in test are given in Table 1. From each mixture of $0.5 \%, 1 \%, 1.5 \%$ and $2 \%$ fiber volume fraction, was compared to conventional concrete and were casted the following specimens are six cubes $(150 \times 150 x 150 \mathrm{~mm})$, six cylinders $(150 \mathrm{~mm}$ dia. and 300mm height) and prisms were casted .

\section{Components of ECC and conventional concrete}

1) Ordinary Portland Cement Ordinary Portland cement or OPC is the general type of cement in use around the world, it is the basic key ingredient for making concrete, mortar,. It is made by intergrinding of argillaceous and calcareous materials. Physical properties of OPC 
2).Consistency The ability of cement paste to flow is known as consistency. The cement paste consistency is determined by using Vicat apparatus when the plunger penetrates by $10 \pm 1 \mathrm{~mm}$ and the corresponding water-cement ratio is reported as the Standard consistency of cement

3) Setting Time: Initial setting time is defined as the time that elapsed from the instant of adding water until the pastes behave as plastic material thus offering resistance against the penetration. Whereas final setting time referred to be the time that is required for the cement paste to reach a certain state of hardness to bear some load and is tested by using Vicat apparatus

4) Soundness The ability of a hardened cement paste to retain its shape after setting is known as soundness. The cement samples containing excessive amounts of free lime and magnesia will result in volume change. Soundness of cement is determined by using Le chartliars apparatus

5) Specific gravity: The particle density which is measured by excluding the air between particles of OPC is found to be in the range of 3.1 to 3.25 . The density of cement is determined by density bottle apparatus and here kerosene is used.

6) PVAfibers

polyvinyl alcohol, were developed some 20 years ago by Kuraray, a Japanese company. When added to concrete or mortar, the fibers develop a molecular and chemical bond with the cement during hydration and curing. .Generally the fiber used in ECC is PVA, One of the remarkable characteristics of this fiber is capable of strong bonding with cement matrix. The layer of $\mathrm{Ca}(\mathrm{OH}) 2$ called as Interfacial transition zone is formed round PVA fiber It is known PVA makes complex cluster with the metal hydroxide of cement matrix. It is pursued that $\mathrm{Ca}+$ and $\mathrm{OH}$ - two different ions in the cement slurry are attracted by PVA fibers and makes layer of $\mathrm{Ca}(\mathrm{OH}) 2$ around the fibers and hence the $\mathrm{Ca}(\mathrm{OH}) 2$ layer plays an important role for bonding strength between the fiber and the matrix

\begin{tabular}{|l|l|}
\hline Type & pva \\
\hline Density & 1.26 \\
\hline Length & 12 \\
\hline Modulus of elasticity & 42.8 \\
\hline Reduction in water & $<2$ \\
\hline Breaking elongation & $<7-15$ \\
\hline Nominal strength & 1620 \\
\hline
\end{tabular}

7) Sand Good river bank sand in absence of any earthy matter and organic matter. Particles are nearly angular in shape passing 250 micron and retaining 150 micron standard sieve. Sample is washed in water to get free from earthy and other organic content and dried over a period of 48 hours of sunlight

\begin{tabular}{|l|l|}
\hline Mix Ingredients & Quantity \\
\hline Cement & \\
\hline Water & $296.13 \mathrm{~kg} / \mathrm{m}^{3}$ \\
\hline Fly Ash & $186 \mathrm{lit} / \mathrm{m}^{3}$ \\
\hline Sand & $150 \mathrm{~kg} / \mathrm{m}^{3}$ \\
\hline Grit (10mm to 4.75mm) & $572.7 \mathrm{~kg} / \mathrm{m}^{3}$ \\
\hline w/c & $1017 \mathrm{~kg} / \mathrm{m}^{3}$ \\
\hline HRWRA (conplast30) & 0.43 \\
\hline
\end{tabular}

8) Super plasticizer This is used to improve the rheological properties of fresh concrete. Super plasticizers are the additives to fresh concrete which helps in dispersing constituents uniformly throughout the mix. which increases workability. Super plasticizer increases slump properties from $5 \mathrm{~cm}$ to $30 \mathrm{~cm}$ without addition of water and thereby reducing the water requirement by 15 to 30 percent. This results in improvement of vital properties like density, water tightness., workability which is in turn required for and no compaction is required. 
9) Fly ash

\begin{tabular}{|l|l|l|}
\hline Class & Discription in ASTM c 618 & $\begin{array}{l}\text { CHEMICAL } \\
\text { REQUIREMENT }\end{array}$ \\
\hline F & $\begin{array}{l}\text { Fly ash normally produced from burning anthracite or } \\
\text { bituminous coalF that meets the applicable requirements for this } \\
\text { class as given herein. This class of fly ash has pozzolanic } \\
\text { properties }\end{array}$ & $\begin{array}{l}\mathrm{SiO} 2+\mathrm{A} 2 \mathrm{O} 3+ \\
\mathrm{Fe} 2 \mathrm{O} 3 \\
\geq 70 \%\end{array}$ \\
\hline C & $\begin{array}{l}\text { Fly ash normally produced from lignite or sub-bituminous coal } \\
\text { that meets theapplicable requirements for this class as given } \\
\text { herein. This class of fly ash, inC addition to having pozzolanic } \\
\text { properties, also has some cementitious properties. Note: Some } \\
\text { Class C fly ashes may contain lime contents higher than 10\%. }\end{array}$ & $\begin{array}{l}\mathrm{SiO} 2 \mathrm{Fe} 3 \\
\mathrm{Fe} 2 \mathrm{O} 2 \mathrm{O} 3+\end{array}$ \\
\hline
\end{tabular}

A. Proportion of Fresh Concrete As percentage of fiber increase, workability decreases compared to initial amount used. Due to addition of more fibers, entrapped air voids increases and therefore these air voids reduces the workability. It becomes difficult to mix as the amount of fiber increases which also leads to cause a finishing problem.

B. Compressive Strength Generally, small amount of replacement of any cementitious material will increase the compressive strength of cube. Same as we replace small quantity of fiber as $0.5 \%$, it will enhance the strength. Enhancement of Polyvinyl Alcohol fibers to the mix increased the 28 day's compressive strength of the mix with the amount of $1 \%$ by $27 \%$ due to limitation provided by

C. Tensile Strength In split tensile strength, it escalate due to Polyvinyl Alcohol fibers at 28 days is approximately $49 \%$ higher than 7 day's strength. It varies from $1.60 \mathrm{MPa}$ to $3.50 \mathrm{MPa}$ for 7 days and 4.38 MPa to $7.02 \mathrm{MPa}$ for 28 days. Tests shows maximum $48 \%$ increases in split tensile strength at 28 days. When compared to conventional concrete Split tensile test give perfect estimation about direct tensile strength due to mixed stress field and fiber orientation but its failure pattern gives good idea about ductility of the material. Failure patterns of splitting tensile test indicate that specimens after first cracking do not separate unlike the concrete failure. Large damage zone is produced due to closely spaced micro cracks surrounding a splitting plane.

\section{Flexural Strength}

Flexural strength also increases as fiber content increases. During the test, it was perceived that PVAECC specimen has greater crack control as demonstrated by reduction in crack widths and crack spacing. Nominal increases remains for all amount of fibers compared to normal mixes

\section{Results and discussion}

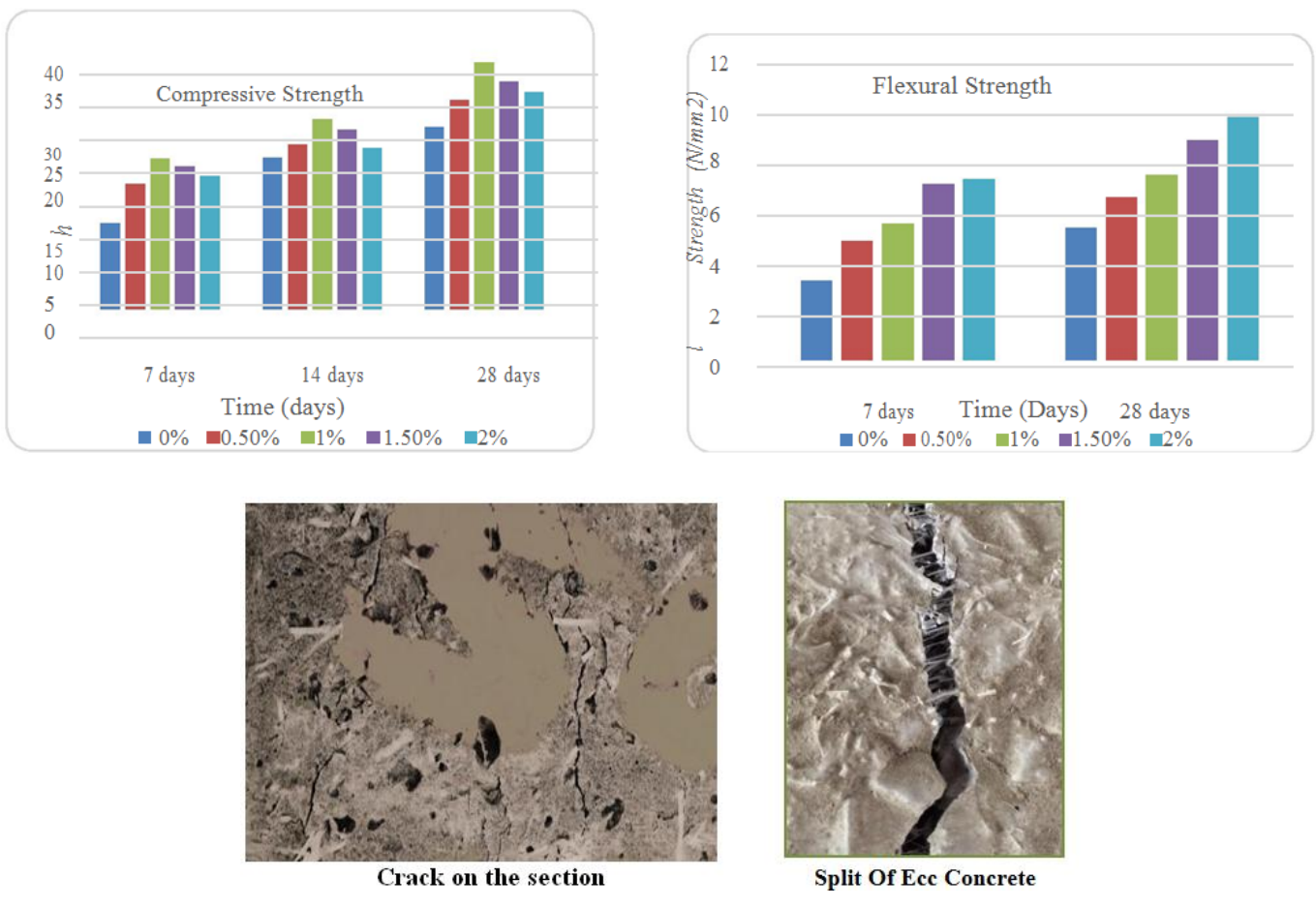



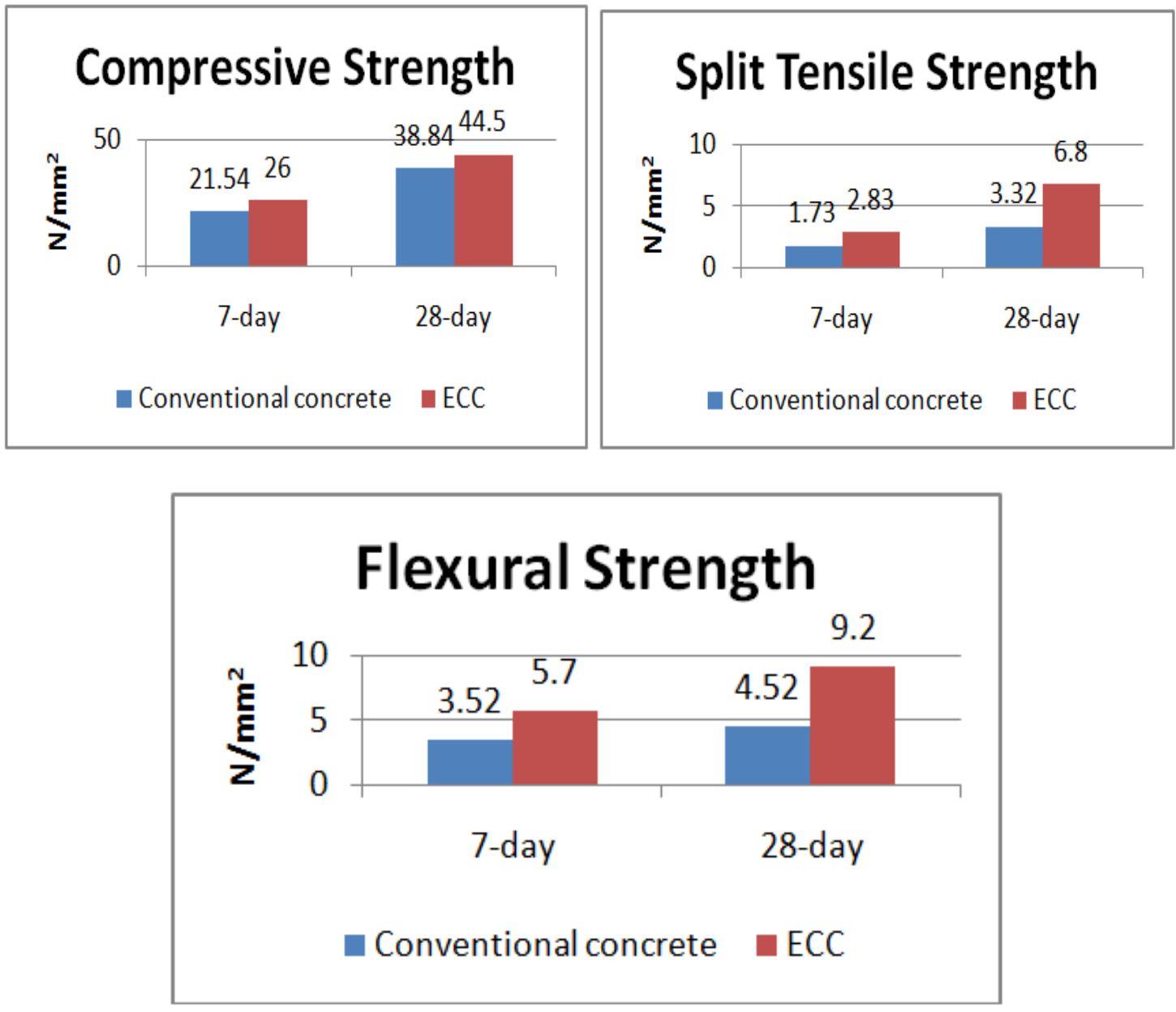

\section{Conclusion}

- The present sudy indicates the comparison between conventional concrete with fly ash of margin of $30 \%$ and ECC -pva with same percent of fly ash

- The conventional concrete shows reduced workability due to addition of fly ash but it increased by addition super plasticizer The studies of the paper shows that there was considerable increase in Flexural strength also increases as fiber content increased.

- Its shows that Compressive strength increases with increasing fiber content. But when it reaches up to its optimum value of $1 \%$, and it starts decreasing with the increasing content of fiber.

- The compressive strength at $1 \%$ is higher than $2 \%$ replacement. Fiber bonding characteristics of concrete increase in review fibers When same split tensile strength was 49\%increase and flexural strength was $48 \%$ increase when compared to conventional concrete

- It was noticed that Fibers reduces the w/c ratio which leads to the low workability but the workability can be maintained by super plasticizers.

- Compared to conventional concrete the fiber reinforced concrete is much tougher and has good compressive strength for 7 days and 28 days and The split tensile strength of the EEC concrete was much better when compared to the conventional concrete

- It was observed that by physical appearance on PVA-ECC specimen has greater crack control as can be seen on surface reduction of crack widths and crack spacing. For conventionl concrete its was obserbed that micro cracks and surface crack were more when compared to ECC

- The cost of ECC is currently about three times that of normal concrete per cubic yard Compared to plain concrete, fiber reinforced concrete is much tougher and more resistant to impact.

The various investigations carried out by several authors related to the development of Engineered Cementitious Composite (ECC) and its applications in the real world proves to be one of the best sustainable concrete materials of the future generations 
An comparative study on Conventional concrete and Engineered Cementitious Composites (ECC-

\section{Journal Papers:}

\section{Reference}

[1]. Evaluation of Engineering CementitiousComposites (ECC) With Different Percentage ofFibers International Journal of Engineering Research \& Technology (IJERT)Vol. 4 Issue 06, June-2015

[2]. Engineered cementitious composites-a review.Chethan.v.r ${ }^{1}$, International Research Journal of Engineering and Technology (IRJET)

[3]. Engineered Cementitious Composites for Structural Applications* Victor Li

[4]. Victor C. Li The ACE-MRL Department of Civil and Environmental Engineering University of Michigan

[5]. Neville A.M, 2005. Properties of concrete, Pearson. Prentice Hall, p 255- 262

[6]. A Literature Review on Engineered Cementitious Composites for Structural applications- Srinivasa. C. H. et al International Journal of Engineering Research \& Technology (IJERT) ISSN: 2278-0181 IJERTV3IS120448 www.ijert.org Vol. 3 Issue12, December-2014

[7]. Studies on flexural behaviour of PVA reinforced bendabale concrete composite- Dr M RameGowda, Ms Uma Devi, Somashekar.N, Rithinkumar M.B,-ICJ,June 2014,vol 88,no 6.pp 25-32

[8]. Evaluation of Engineering Cementitious Composites (ECC) With Different Percentage of Fibers Bhaumik Merchant IJERT Vol. 4 Issue 06, June-2015

\section{Codes Books}

[9]. IS 5816:1999, Splitting Tensile Strength Of Concrete

[10]. IS 516:1959 (Eighteenth reprint JUNE 2006) Method Of Tests For Strength Of Concrete

[11]. IS 4031 (Part 11):1988; Methods Of Physical Tests For Hydraulic Cement 